\title{
Characterization of Inhibition of the Spinal Nociceptive Tail-Flick Reflex in the Rat from the Medullary Lateral Reticular Nucleus
}

\author{
G. F. Gebhart and M. H. Ossipov' \\ Department of Pharmacology, College of Medicine, University of lowa, lowa City, lowa 52242
}

\begin{abstract}
Inhibition of the spinal nociceptive tail-flick (TF) reflex by focal electrical stimulation in the caudal medulla was examined and characterized in lightly pentobarbital-anesthetized rats. Systematic mapping studies revealed that inhibition of the TF reflex was produced at low intensities of stimulation $(12.5-25 \mu \mathrm{A})$ only from the lateral reticular nucleus (LRN). Areas dorsal and medial to the LRN required higher intensities of stimulation to produce descending inhibition of the $T F$ reflex, likely reflecting spread of current to the LRN at these higher intensities of stimulation (50-100 $\mu \mathrm{A})$. At threshold inhibitory intensities of stimulation in the LRN, changes in blood pressure were not produced. Strength-duration characterization of stimulation and the microinjection of glutamate into the LRN at the same site where focal electrical stimulation was effective suggest that the descending inhibition produced arises from activation of cell bodies in the LRN. The intrathecal administration of a variety of pharmacological antagonists revealed the descending inhibition produced by stimulation in the LRN to be mediated at least in part by spinal $\alpha_{2}$-adrenoceptors. These findings, together with previous observations, suggest a role for the LRN in the centrifugal modulation of spinal nociceptive transmission.
\end{abstract}

The role of medial brain stem structures in centrifugal modulation of spinal nociceptive transmission has been the focus of many investigations. Focal electrical stimulation in the midbrain periaqueductal gray and rostral ventral medullary nucleus raphe magnus has been established to significantly attenuate spinal nociceptive reflexes (Sandkühler and Gebhart, 1984a; Zorman et al., 1981), as well as spinal dorsal horn neuronal excitation produced by noxious peripheral stimuli (e.g., Fields et al., 1977; Gebhart, 1985; Liebeskind et al., 1973). Stimulation in more rostral periventricular-medial hypothalamic (Carstens, 1982) and medial preoptic-septal (Carstens et al., 1982) sites also significantly attenuates the noxious-evoked responses of lumbar spinal dorsal horn neurons, suggesting the presence of a functionally homogenous system of descending inhibition medially in the brain. However, electrical stimulation in sites lateral in the midbrain and in the lateral rostral ventral medulla also significantly attenuate both nociceptive reflexes and noxious-evoked spinal dorsal horn neuronal responses (e.g., Carstens et al., 1980; Dostrovsky et al., 1982; Fields et al., 1977; Sandkühler and Gebhart, 1984a; Zorman et al., 1981). Moreover, the effective intensities of stimulation at these relatively

\footnotetext{
Received Mar. 19, 1985; revised June 10, 1985; accepted June 11, 1985.

We gratefully acknowledge the technical assistance of Michael Burcham and secretarial assistance of Elizabeth McDonald. Naloxone and phentolamine were graciously provided by DuPont and Ciba Pharmaceuticals, respectively. This work was supported by awards DA 02879 and NS 19912; M.H.O. was supported by T32 MH 15172.

Correspondence should be addressed to G. F. Gebhart.

' Present address: Anaquest, BOC Group, 100 Mountain Avenue, Murray Hill, NJ 07974.

Copyright (C) 1986 Society for Neuroscience $0270-6474 / 86 / 030701-13 \$ 02.00 / 0$
}

lateral sites are generally less than is required at medial sites in the brain stem (Carstens et al., 1980; Dostrovsky et al., 1982; Sandkühler and Gebhart, 1984a). Further, the modulation of spinal nociceptive transmission from the reticular formation lateral in the midbrain differs qualitatively from that produced by stimulation medially in the midbrain periaqueductal gray (Carstens et al., 1980). Clearly, there exist multiple descending pathways capable of modulating spinal nociceptive transmission (e.g., Gebhart et al., 1983b; Sandkühler and Gebhart, 1984b).

The contribution of the caudal medullary lateral reticular nucleus (LRN) to tonic descending inhibition (Hall et al., 1982) and to nociceptive processing in the spinal dorsal horn of the cat has been considered only recently (Morton et al., 1983). It has been established anatomically (Beitz et al., 1983) and physiologically (Gebhart et al., 1983b; Sandkühler and Gebhart, 1984b) that descending pathways in the rostral ventral medulla coursing either medially or laterally can serve as functionally important relays for the centrifugal modulation of nociception produced by stimulation in the midbrain. Results of Morton et al. (1984) suggest a similar conclusion, pointing to a role for the caudal medullary LRN in descending inhibition of spinal nociceptive transmission. In the present study, inhibition of the spinal nociceptive tail-flick (TF) reflex in the lightly pentobarbital-anesthetized rat was studied and characterized as: (1) produced by low intensities of focal electrical stimulation only from and immediately surrounding the LRN in the caudal medulla, (2) resulting from activation of cell bodies in the LRN, and (3) mediated by spinal $\alpha_{2}$-adrenoceptors. Portions of these data have been reported previously (Gebhart and Ossipov, 1984; Ossipov and Gebhart, 1984).

\section{Materials and Methods}

\section{Animals}

Experiments were performed on adult male Sprague-Dawley albino rats (King Laboratories, Oregon, WI) weighing 250-350 gm on the day of surgery. Rats were initially anesthetized with $35-45 \mathrm{mg} / \mathrm{kg}$ of pentobarbital sodium (Nembutal) administered intraperitoneally. Wound margins were covered with a local anesthetic ointment. Following surgery (cannulation of a femoral vein and artery and craniotomy), a light level of anesthesia (corneal, auricular-pinnal, and flexion reflexes present) was maintained throughout the duration of the experiment by an intravenous infusion of a solution containing $5 \mathrm{mg} / \mathrm{ml}$ of pentobarbital (3-6 mg/kg/hr); experiments typically lasted 4-6 hr. Arterial blood pressure and body temperature (rectal thermistor probe) were monitored continuously. The rats werc warmed with a watcr-circulating heating pad to maintain body temperature at $37 \pm 0.5^{\circ} \mathrm{C}$.

In this and other studies (Fields et al., 1983; Jones and Gebhart, 1986; Sandkühler and Gebhart, 1984a, b; Tseng et al., 1983; Zorman et al., 1981,1982 ), the TF reflex in the lightly pentobarbital-anesthetized rat has been observed to be qualitatively similar to that in the waking rat. The TF reflex and the stimuli that evoke it and other nociceptive reflexes in the lightly anesthetized state are unchanged. Pinching the hind limb or tail with toothed forceps evokes only withdrawal; changes in blood pressure, vocalization, or coordinated complex movements are not pro- 
duced. If, however, the level of anesthesia is allowed to lighten further, rats will show apparent signs of discomfort (e.g., chewing and whisker movement, increases in blood pressure during heating of the tail, spread of the reflex, etc.; see Fields et al., 1983). Care is taken to maintain an appropriate level of anesthesia by adjusting the rate of infusion of pentobarbital. The appropriateness of the level of anesthesia and the status of the animal is continuously monitored by watching for changes in blood pressure, sustained responses to heating of the tail, and initiation of spontaneous movements. Rats can be maintained without discomfort in a state of relatively light anesthesia throughout the duration of an experiment; both the blood pressure and the latency of the TF reflex are stable over long periods of time (see Fig. 1 in Sandkühler and Gebhart, 1984a), suggesting that neither the surgery nor possible discomfort from the stereotaxic apparatus produces nociceptive input that could conceivably activate inhibitory control mechanisms. Indeed, the TF reflex in the lightly pentobarbital-anesthetized rat is often of shorter latency and more vigorous than in the waking state (Sandkühler and Gebhart, 1984a). These experiments were conducted in accordancc with guidelines established by the International Association for the Study of Pain.

\section{Nociceptive TF reflex}

Focused radiant heat $(4 \times 10 \mathrm{~mm}$ area $)$ applied to the underside of the tail $2,4,6,8$, and $10 \mathrm{~cm}$ from its distal end was employed to evoke the nociceptive TF reflex. The tail position at which heat was applied was varicd systematically to minimize possible damage to the tail; the same tail position was not heated twice in succession. No differences in control TF latencies were observed among the different tail positions stimulated. A cutoff time of $7 \mathrm{sec}$, which was greater than three times the baseline TF latency in the lightly anesthetized state, was employed to minimize damage to the skin of the tail. Noxious heating of the tail was given every 2-3 min; this interval produced a stable nociceptive TF reflex for the duration of the experiment. The TF reflex in the lightly pentobarbital-anesthetized rat has been fully described elsewhere (Sandkühler and Gebhart, 1984a). When brain stimulation (see below) was effective in inhibiting the TF reflex, a control TF in the absence of brain stimulation always followed at the next 2-3 min interval.

\section{Brain stimulation}

Focal electrical brain stimulation consisted of continuous $100 \mathrm{~Hz}$ constant-current cathodal pulses of $100 \mu \mathrm{sec}$ duration. Brain stimulation was started $10 \mathrm{sec}$ before and continued during noxious heating of the tail until a TF reflex occurred or $7 \mathrm{sec}$ had elapsed. This stimulation paradigm was determined experimentally to require the lowest intensity of stimulation to inhibit the TF reflex (Fig. $1 A$ ). Monopolar stimulating electrodes, guided stereotaxically in the vertical plane (incisor bar at $+3.3 \mathrm{~mm}$; Paxinos and Watson, 1982), were used throughout. In the mapping experiments, insulated tungsten or stainless steel microelectrodes $(0.25 \mathrm{~mm}$ shank diameter) having tip diameters of approximately 50-70 $\mu \mathrm{m}$ were used. The stimulation current was increased stepwise $(6.25,12.5,18.75,25,31.25,37.5,43.75,50,62.5,75,100,125,150$, and $200 \mu \mathrm{A}$ ) until the threshold for inhibition of the TF reflex was determined or non-antinociceptive effects of stimulation were observed (e.g., changes in blood pressure, apnea, muscle flexion/extension, etc.). In other experiments, 34 gauge $(0.15 \mathrm{~mm}$ O.D.) insulated magnet wire (tough-pitch copper wire; Belden, Richmond, IN) inserted through a 26 gauge $(0.45 \mathrm{~mm}$ O.D.) guide cannula was used. In these experiments, the electrodes extended ventrally $2 \mathrm{~mm}$ beyond the end of the guide cannula. The indifferent electrode (anode) in all experiments was a needle inserted subcutaneously in the lumbar region of the back.

\section{Glutamate microinjection}

The excitatory amino acid S-glutamate is widely believed to directly and selectively excitc ncuronal somata and dendrites (e.g., Goodchild et al., 1982; Johnson, 1972; Puil, 1981). Thus, inhibition of the TF reflex by S-glutamate microinjected into the same site where electrical stimulation is effective suggests that focal electrical stimulation produces inhibition of the TF reflex by an influence on cell bodies. MonosodiumS-glutamate (50-200 mM) was microinjected in the medulla in volumes of $0.2-0.5 \mu \mathrm{l}$ via an injection cannula (33 gauge, $0.20 \mathrm{~mm} \mathrm{O.D.)} \mathrm{inserted}$ through and extending $2 \mathrm{~mm}$ beyond the end of the 26 gauge guide cannula. S-glutamate was dissolved in physiological saline, filtered (22 $\mu \mathrm{m}$ Millipore), and microinjected into 35 caudal medullary sites in 12 experiments. The progress of the microinjection was continuously mon- itored by following the progress of an air bubble in a length of calibrated tubing between the injection syringe and the injection cannula.

\section{Intrathecal injection}

Intrathecal cannulae (PE-10 tubing; $7.5-8 \mathrm{~cm}$ in length) were implanted in 24 rats as described by Yaksh and Rudy (1976). The following pharmacologic antagonists and doses were employed: haloperidol hydrochloride (5-10 $\mu \mathrm{g} ; 5 \mu \mathrm{g}$ in $2 \mu \mathrm{l})$; methysergide dimaleate (15-30 $\mu \mathrm{g} ; 15$ $\mu \mathrm{g}$ in $7.5 \mu \mathrm{l})$; naloxone hydrochloride $(10-20 \mu \mathrm{g} ; 10 \mu \mathrm{g}$ in $4 \mu \mathrm{l})$; phentolamine hydrochloride $(15-30 \mu \mathrm{g} ; 15 \mu \mathrm{g}$ in $10 \mu \mathrm{l})$; atropine sulfate (4 $\mu \mathrm{g}$ in $8 \mu \mathrm{l})$; yohimbine hydrochloride $(15-30 \mu \mathrm{g} ; 15 \mu \mathrm{g}$ in $10 \mu \mathrm{l})$; prazosin hydrochloride (15-30 $\mu \mathrm{g} ; 15 \mu \mathrm{g}$ in $10 \mu \mathrm{l})$; propranolol hydrochloride $(10$ $\mu \mathrm{g}$ in $4 \mu \mathrm{l})$; and $\mathrm{D}-\mathrm{Pro}^{2}, \mathrm{D}-\mathrm{Phe}^{7}$, D-Trp ${ }^{9}$-substance $\mathrm{P}(15-30 \mu \mathrm{g} ; 15 \mu \mathrm{g}$ in $3 \mu \mathrm{l})$. Doses were selected on the basis of literature reports and previous experience (e.g., Jones and Gebhart, 1986; Sagen and Proudfit, 1984; Schmauss et al., 1983). The progress of the intrathecal injection was continuously monitored by observing the travel of an air bubble in a length of calibrated PE-10 tubing between the intrathecal catheter and the injection syringe. To insure that each pharmacologic antagonist had access to the lumbar spinal cord, $6 \mu$ l of artificial CSF was flushed through the intrathecal catheter immediately after administration of an antagonist.

\section{Histology}

Rats were killed with intravenous injections of pentobarbital and potassium chloride. Anodal electrolytic lesions ( $500 \mu \mathrm{A} \mathrm{DC}$ for $3 \mathrm{sec}$ ) were made to identify sites of stimulation and of microinjection of S-glutamate in cresyl violet-stained coronal brain sections. Fast green dye (6 $\mu$ l) was injected via the intrathecal catheter, and the spinal cord removed (De Sousa and Horrocks, 1979) to measure the placement of the end of the intrathecal catheter and to inspect the spinal cord for damage.

Statistical comparisons were made employing Student's $t$ test (paired or grouped) or analyses of variance followed by Dunnett's test where appropriate; $p<0.05$ was considered significant. Data are presented as means \pm SEM.

\section{Results}

\section{$L R N$ stimulation}

Stimulation in the LRN (LRNS) was characterized by its strength-duration relationship (see below), by the optimum interval between the onset of LRNS and initiation of noxious heating of the tail, and by whether the inhibitory effect of conditioning LRNS outlasted the period of LRNS. It was previously determined that $10 \mathrm{sec}$ was the optimum interval between the onset of conditioning brain stimulation in the midbrain and heating of the tail (Sandkühler and Gebhart, 1984a). In the present study, varying intervals between the onset of conditioning LRNS and heating of the tail were examined and $10 \mathrm{sec}$ found to be the optimum interval (Fig. $1 A$ ). Stimulation in the LRN for $20 \mathrm{sec}$ before the onset of heating the tail did not change the minimum threshold intensity of LRNS. LRNS started 5 or $2 \mathrm{sec}$ before or concurrent with $(0 \mathrm{sec})$ heating the tail required higher intensities of stimulation to inhibit the TF reflex (e.g., $34.38 \pm 4.49 \mu \mathrm{A}=109 \%$ of the minimal LRNS threshold at time 0 ). It does not appear that temporal summation is required for inhibition of the TF reflex by LRNS, since LRNS started 2 sec after the onset of heating the tail also inhibited the TF reflex; the mean pre-LRNS TF latency in these five animals was $1.96 \pm$ $0.13 \mathrm{sec}$, corresponding to a skin temperature of approximately $44^{\circ} \mathrm{C}$. The experimental design is graphically portrayed in the inset of Figure $1 \mathrm{~A}$.

In nine different rats, the inhibitory effect of $10 \mathrm{sec}$ of conditioning LRNS was determined not to outlast the duration of LRNS (Fig. 1B). At no time tested between 0 and $90 \mathrm{sec}$ following termination of LRNS was the TF latency greater than the control TF latency determined before initiation of LRNS.

\section{Mapping experiments}

Systematic electrode penetrations to map TF inhibitory stimulation thresholds were made rostrocaudally and at $0.5 \mathrm{~mm}$ 

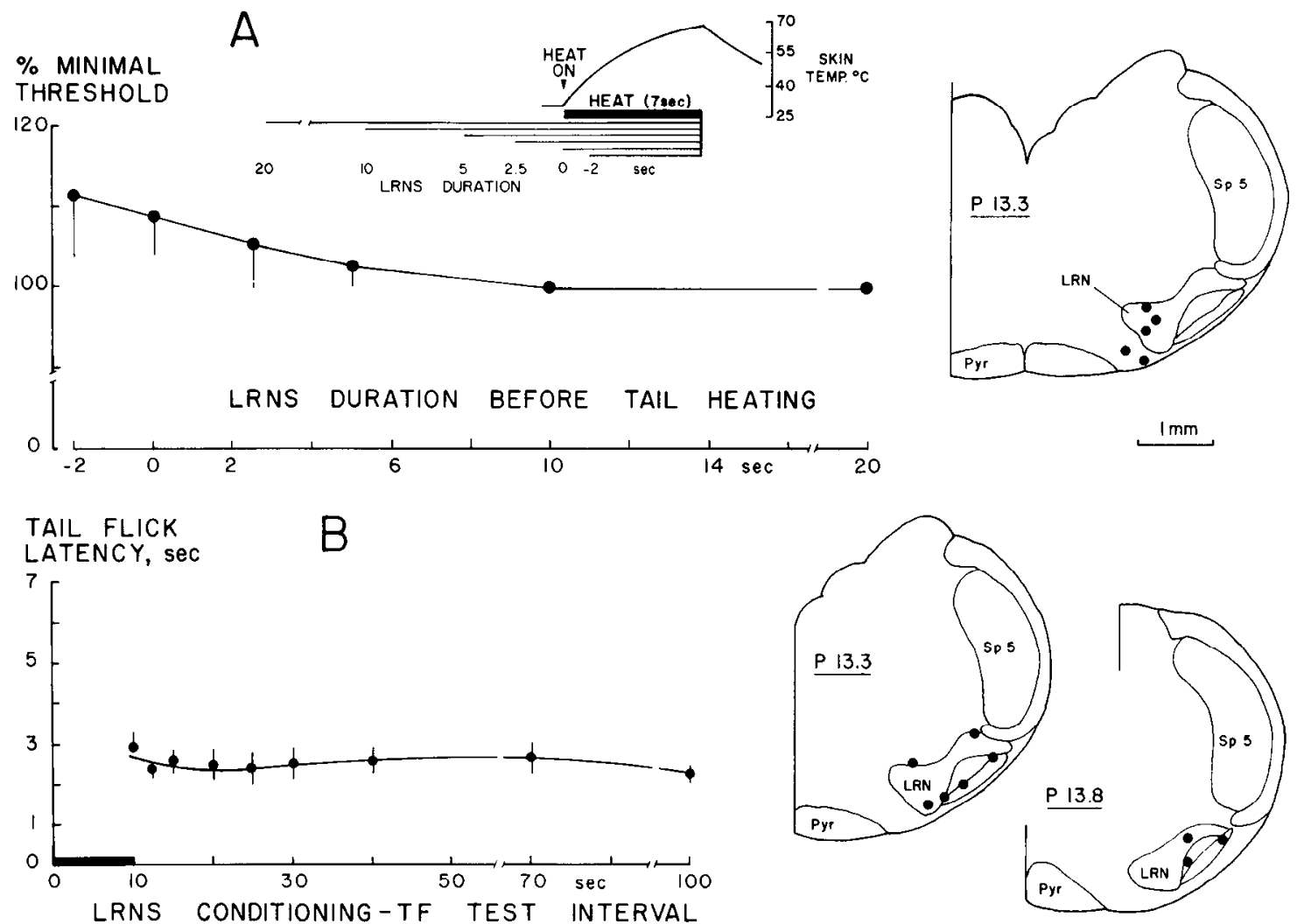

Figure 1. A, Effect of varying the duration of conditioning stimulation in the lateral reticular nucleus (LRNS) before initiation of tail heating on the threshold for inhibition of the TF reflex. LRNS continued during heating of the tail until the 7 sec cutoff. Inset, The LRNS-tail heating paradigm; horizontal lines indicate the onset and duration of LRNS relative to initiation of tail heating (Heat On). Data are portrayed as mean percent of the minimal TF inhibitory threshold \pm SEM $(32.3 \pm 4.68 \mu \mathrm{A}, n=5)$. $B$, Effect of conditioning stimulation in the LRN on the TF latency. TF latency $(\mathrm{sec})$ is plotted against time from the onset of $10 \mathrm{sec}$ of LRNS $(20.14 \pm 1.34 \mu \mathrm{A}$ at $100 \mathrm{~Hz}$; black bar). Data are portrayed as means \pm SEM; the mean control TF latency was $2.22 \pm 0.16 \mathrm{sec}(n=10)$. The stimulation sites for the data portrayed in $A$ and $B$ are indicated on representative coronal brain sections (Paxinos and Watson, 1982). Pyr, Pyramidal tract; $L R N$, lateral reticular nucleus; $S p$ 5, spinal trigeminal nerve.

intervals dorsoventrally and mediolaterally in the caudal medulla. At each stimulation site, the current threshold for inhibition of the TF reflex was determined (where possible). Diagrammatic representation of electrode tracks $0.5-2.5 \mathrm{~mm}$ lateral to the midline in a single coronal plane is presented in Figure 2 . In the electrode track $0.5 \mathrm{~mm}$ medial to the midline, no stimulated sites inhibited the TF reflex at any stimulation intensity, up to $200 \mu \mathrm{A}$. Stimulation applied near and in the pyramidal tract did produce muscle flexions. More lateral electrode tracks passing near or through the LRN did inhibit the TF reflex; current intensities required to inhibit the TF reflex were lowest within the LRN itself. Stimulation at sites dorsal in the caudal medulla was without effect on the TF reflex but often elicited increases in blood pressure and/or other effects (e.g., apnea, flexions of facial musculature), particularly in the lateral-most electrode track passing through the spinal nucleus of the trigeminal nerve. There was no significant correlation found between increases in mean blood pressure and the stimulation threshold required to inhibit the TF reflex. Indeed, at threshold inhibitory intensities of LRNS, changes in blood pressure were not observed or were small in magnitude (e.g., $\pm 5 \mathrm{mmHg}$ ).

Likewise, electrode tracks through the rostral and caudal aspects of the LRN inhibited the TF reflex only when stimulation was applied in or near the LRN itself, and the lowest intensities of stimulation for inhibition of the TF reflex $(\leq 25 \mu \mathrm{A})$ were within the LRN (Fig. $3 A$ ). The data from the mapping experiments are summarized in a composite representation in Figure $3 B$. Only within and immediately adjacent to the LRN, particularly the relatively lateral LRN, did stimulation intensities $\leq 25$ $\mu \mathrm{A}$ inhibit the TF reflex. Inhibitory threshold contours between 25-50 and 50-100 $\mu \mathrm{A}$ extended medially and dorsally away from the LRN, likely representing current spread to the LRN at these higher intensities of stimulation. Current spread was considered to be minimal at low intensities of stimulation within the LRN; changes in electrode position of as little as $0.2 \mathrm{~mm}$ were observed to change the threshold for inhibition of the TF reflex by as much as $50 \%$.

\section{Strength-duration relationship}

In an attempt to determine which neural elements are affected by stimulation in the LRN, the strength-duration relationship of LRNS was evaluated by systematically varying the pulse duration ( $\mu \mathrm{sec})$ and determining the constant-current strength $(\mu \mathrm{A})$ required to inhibit the TF reflex (i.e., TF latency $\geq 7 \mathrm{sec}$ ). The data from seven experiments are plotted in linear and log$\log$ fashion in Figure 4 ( $A$ and $B$, respectively). From these strength-duration curves, the chronaxie of stimulation was determined. Chronaxie is defined as the time (pulse duration in $\mu \mathrm{sec}$ ) on the strength-duration curve at twice the asymptotic minimum current (i.e., the rheobase current, $I_{r}$ ) required to inhibit the TF reflex at long pulse durations. The chronaxie of stimulation was found to be $92 \mu \mathrm{sec}$ for monopolar stimulating electrodes having tip diameters of 50-70 $\mu \mathrm{m}$ and 190-195 $\mu \mathrm{sec}$ for electrodes with relatively larger tip diameters $(200 \mu \mathrm{m})$. As expected, the rheobase current was also greater for the larger diameter electrodes $(44 \mu \mathrm{A})$ than for the smaller diameter electrodes $(20 \mu \mathrm{A})$. 

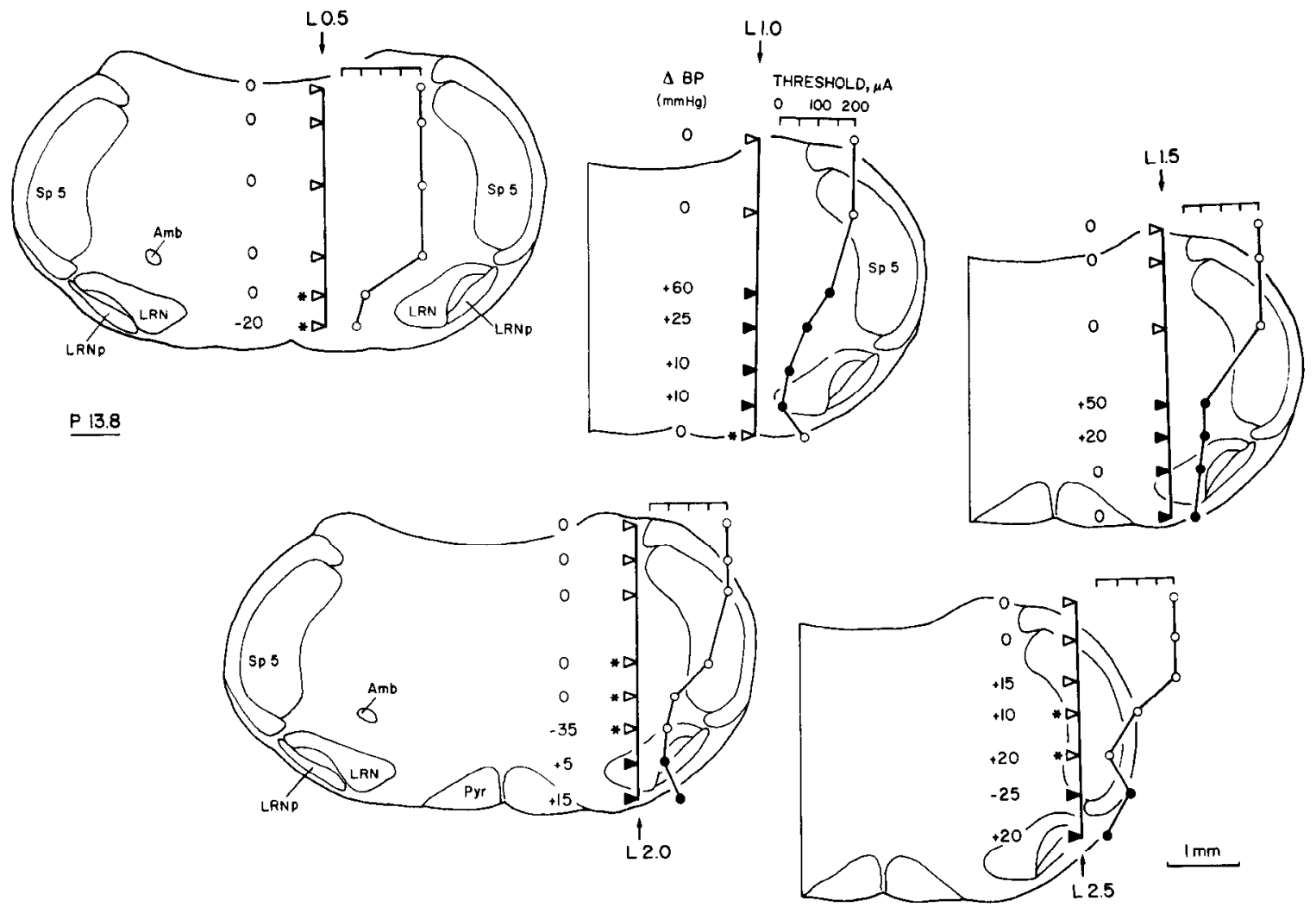

Figure 2. Histologic reconstruction of five electrode tracks (vertical lines) in the same rostrocaudal plane (P 13.8) 0.5-2.5 mm lateral to the midline. Filled symbols indicate thresholds for inhibition of the TF reflex $(\bullet)$ at the sites of stimulation $(\bullet)$ portrayed along the vertical electrode tracks. Open symbols along the electrode tracks indicate where non-antinociceptive effects were produced $(* D)$ at the indicated intensity of stimulation (without inhibition of the TF reflex) or sites where the TF reflex was not inhibited by intensities of stimulation up to $200 \mu \mathrm{A}(D)$. Changes in blood pressure $(\triangle B P, \mathrm{mmHg})$ produced by stimulation are shown to the left of the tracks; + and - represent increases and decreases, respectively. Amb, Nucleus ambiguus; $L R N p$, LRN parvocellular; other abbreviations as in Fig. 1.

\section{Glutamate microinjections}

A total of 36 microinjections of monosodium-S-glutamate $(50$, 100 , or $200 \mathrm{~mm}$ ) were administered in 35 sites in 12 rats. The mean LRNS threshold for inhibition of the TF reflex in these experiments was $23.16 \pm 1.70 \mu \mathrm{A}$. Typically, the microinjection of glutamate produced inhibition of the TF reflex within 10-30 sec of injection; the TF latency typically returned to baseline within $10 \mathrm{~min}$ (Fig. $5 A$ ). No reliable dose-response relationship was observed; the greater concentration (i.e., $200 \mathrm{~mm}$ ) of glutamate produced an effect essentially similar in magnitude and duration to the lowest $(50 \mathrm{~mm}$ ) concentration of glutamate (Fig. $5 B$ ). Four of 13 sites into which $50 \mathrm{~mm}$ glutamate was microinjected and all six sites in the LRN into which $100 \mathrm{~mm}$ glutamate was microinjected produced at least a doubling of the TF latency from pretreatment control (Fig. 5C). Of those sites within the LRN at which $200 \mathrm{~mm}$ glutamate was administered, several failed to increase the TF latency at all (Fig. 5C), which was possibly due to the production of lesions apparent on subsequent histological examination. Microinjections of glutamate outside of the LRN did not inhibit the TF reflex. Glutamate microinjection frequently $(23 / 36)$ produced changes in blood pressure. The effects produced ranged from decreasing blood pressure by $90 \mathrm{mmHg}$ to increasing it by $75 \mathrm{mmHg}$. There was no significant correlation between changes in blood pressure and either the site of injection of glutamate or the pretreatment LRNS threshold for inhibition of the TF reflex. There was also no significant correlation between the duration of action of glutamate's inhibition of the TF reflex and changes in blood pressure.

\section{Intrathecal administration of receptor antagonists}

Selected synaptic rcceptor antagonists wcrc administcred intrathecally in an effort to determine the transmitter(s) at the level of the lumbar spinal cord mediating the inhibitory effect of LRNS on the TF reflex. Since the intensity of stimulation required to inhibit the TF reflex can increase slightly with repeated stimulation before a stable inhibitory threshold is attained (Jones and Gebhart, 1986; Sandkühler and Gebhart, $1984 \mathrm{a}, \mathrm{b})$, the pretreatment LRNS inhibitory threshold was defined as three consecutive inhibitions of the TF reflex (each followed by a control TF) at the same threshold intensity of stimulation. In the LRN, the mean initial inhibitory threshold was $18.75 \pm 1.03 \mu \mathrm{A}$, which increased to a stable $21.87 \pm 0.79$ $\mu \mathrm{A}(n=45)$. Pretreatment LRNS inhibitory thresholds for the different groups ranged from 17.5 to $25.0 \mu \mathrm{A}$ (Table 1); the pretreatment LRNS inhibitory thresholds did not differ among the groups.

Among the nine antagonists tested, only the nonselective adrenoceptor antagonist phentolamine, the $\alpha_{2}$-selective antagonist yohimbine, and the putative serotonin antagonist methysergide significantly increased the LRNS threshold for inhibition of the TF reflex. The intrathecal administration of naloxone, atropine, prazosin, haloperidol, propranolol, and the substance $P$ antagonist was without significant influence on the LRNS threshold for inhibition of the TF reflex (Table 1). Examples of the onset and duration of action of phentolamine and yohimbine are given in Figure 6; data for five of the antagonists are summarized in Figure 7. Methysergide $(30 \mu \mathrm{g})$ was tested in 10 rats (Fig. $7 B$ ), 

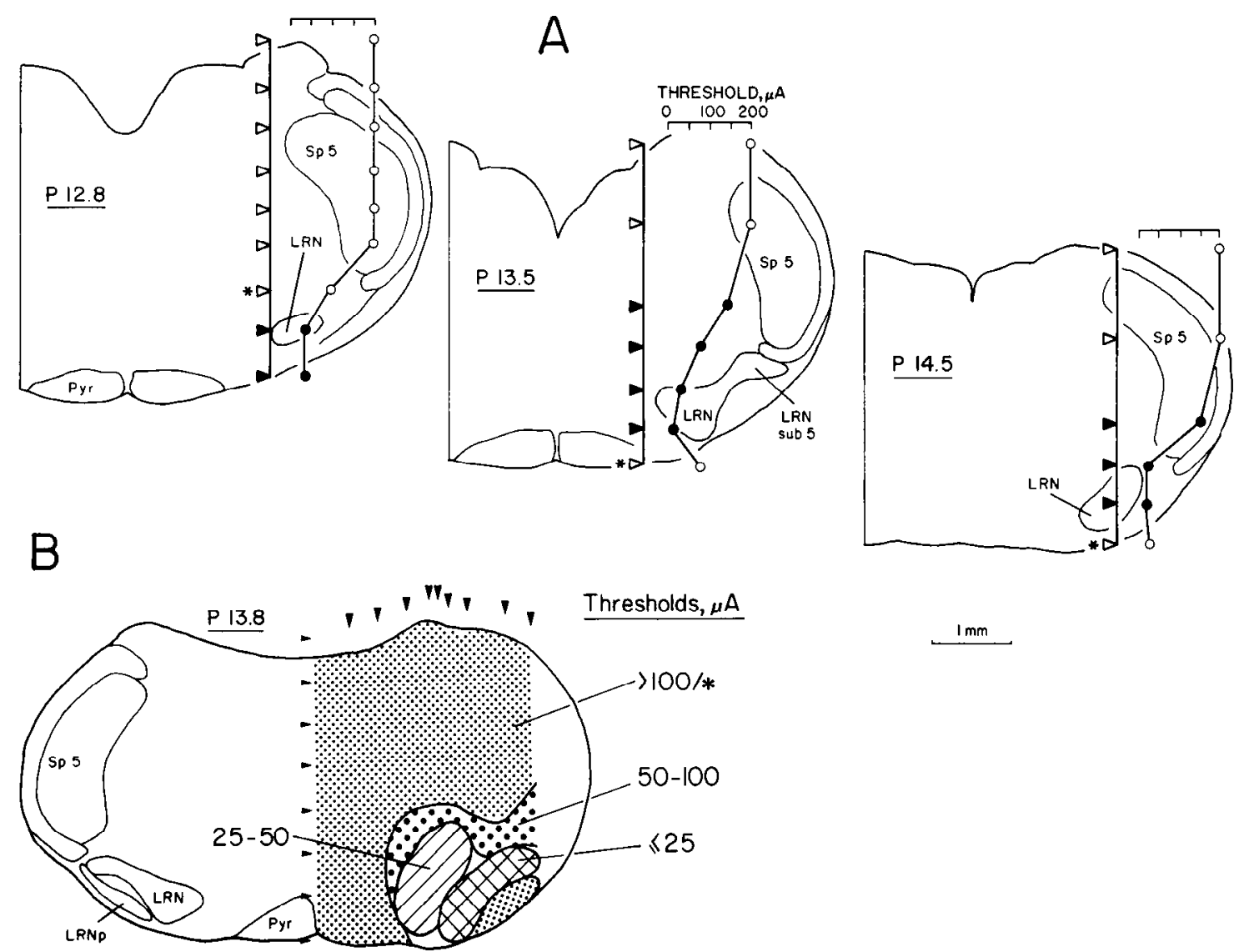

Figure 3. A, Histologic reconstruction of electrode tracks (vertical lines) at three different rostrocaudal levels of the caudal medulla (Paxinos and Watson, 1982). See legend to Figs. 1 and 2 for details and abbreviations. $B$, Diagrammatic summary of stimulation thresholds for inhibition of the TF reflex drawn on a representative coronal brain section. The thresholds $(\mu \mathrm{A})$ for inhibition of the TF reflex are indicated: $>100 / *$ indicates no inhibition of the TF reflex at intensities of stimulation $>100 \mu \mathrm{A}$ and up to $200 \mu \mathrm{A}$ or non-antinociceptive effects at intensities of stimulation ranging between 6.25 and $200 \mu \mathrm{A}$. This summary diagram was constructed from nine electrode tracks through the caudal medulla ( $\nabla)$.

and its effect on the LRNS threshold was statistically significant, but quite variable. In four cascs, methyscrgide increased the stimulation threshold in the LRN for inhibition of the TF reflex by $\geq 50 \%$; in four other cases, methysergide had no influence on the LRNS threshold (e.g., Fig. 6A). The effects of phentolamine and yohimbine on the LRNS threshold, on the other hand, were greater and more consistent. The $\alpha_{2}$-selective adrenoceptor antagonist yohimbine produced rapid, dose-dependent, time-limited increases in the LRNS threshold in all animals to which it was administered (Figs. $6 C$ and $7 E$; Table 1). The effect of phentolamine on the LRNS threshold was significant only at the greater $30 \mu \mathrm{g}$ dose; an increase in the LRNS threshold $\geq 50 \%$ was produced in seven of ten rats. It should be noted that, for increases in the LRNS threshold to have been considered reliable, it was required that the threshold return toward the pretreatment, previously established stable, threshold (e.g., Fig. 6). The dopamine-, $\alpha_{1}$-, and $\beta$-receptor antagonists haloperidol, prazosin, and propranolol did not significantly affect the LRNS threshold. These results suggest that the descending inhibition produced by stimulation in the LRN is mediated, at least in part, by spinal $\alpha_{2}$-adrenoceptors.

The data presented in Table 2 suggest also that the TF reflex is under a tonic noradrenergic inhibitory influence. The intrathecal administration of phentolamine or yohimbine significantly reduced the baseline TF latency (see Fig. $6 \mathrm{C}$ ). The intrathecal administration of D-Pro ${ }^{2}$, D-Phe ${ }^{7}, \mathrm{D}-\mathrm{Trp}^{9}$-substance $\mathrm{P}$, on the other hand, produced variable effects on the nociceptive TF reflex. In two of five rats, both the 15 and $30 \mu \mathrm{g}$ doses (Table
2) inhibited the TF reflex (i.e., TF latency $\geq 7 \mathrm{sec}$ ) within 10 min after intrathecal administration. The TF latency of the rcmaining six rats was unchanged. However, in all rats to which the putative substance $\mathbf{P}$ antagonist was administered, blood pressure increased between 5 and $40 \mathrm{mmHg}$ with a variable latency to onset between 2 and $25 \mathrm{~min}$ following administration. Rats in which the greatest increase in blood pressure was observed were not those in which the TF latency was longest. When tested at the time of peak increase in blood pressure, the LRNS threshold for inhibition of the TF reflex was unaffected (Table 1) in those rats in which the TF reflex was not blocked by the putative antagonist.

\section{Discussion}

Converging anatomical and electrophysiological evidence suggests that the LRN may function as a sensory relay to sites rostral in the brain (as well as to the cerebellum) or as a site of sensorimotor integration. Classically, the LRN has been considered to be a major relay for cerebellar afferents (Dietrichs and Walberg, 1979; Künzle, 1973; Verhaart, 1957; Walberg, 1952). Recent studies, however, have established that the LRN is perhaps more densely supplied with spinal afferents than any other supraspinal site in the rat (Menetrey et al., 1983), suggesting a role for the LRN beyond that of a relay for cerebellar afferents. Injection of HRP into the LRN labeled more spinal neurons than equivalent injections into the thalamus or bulbar reticular formations (Chaouch et al., 1983; Menetrey et al., 1982). Significantly, neurons of the marginal layers of the spinal dorsal 


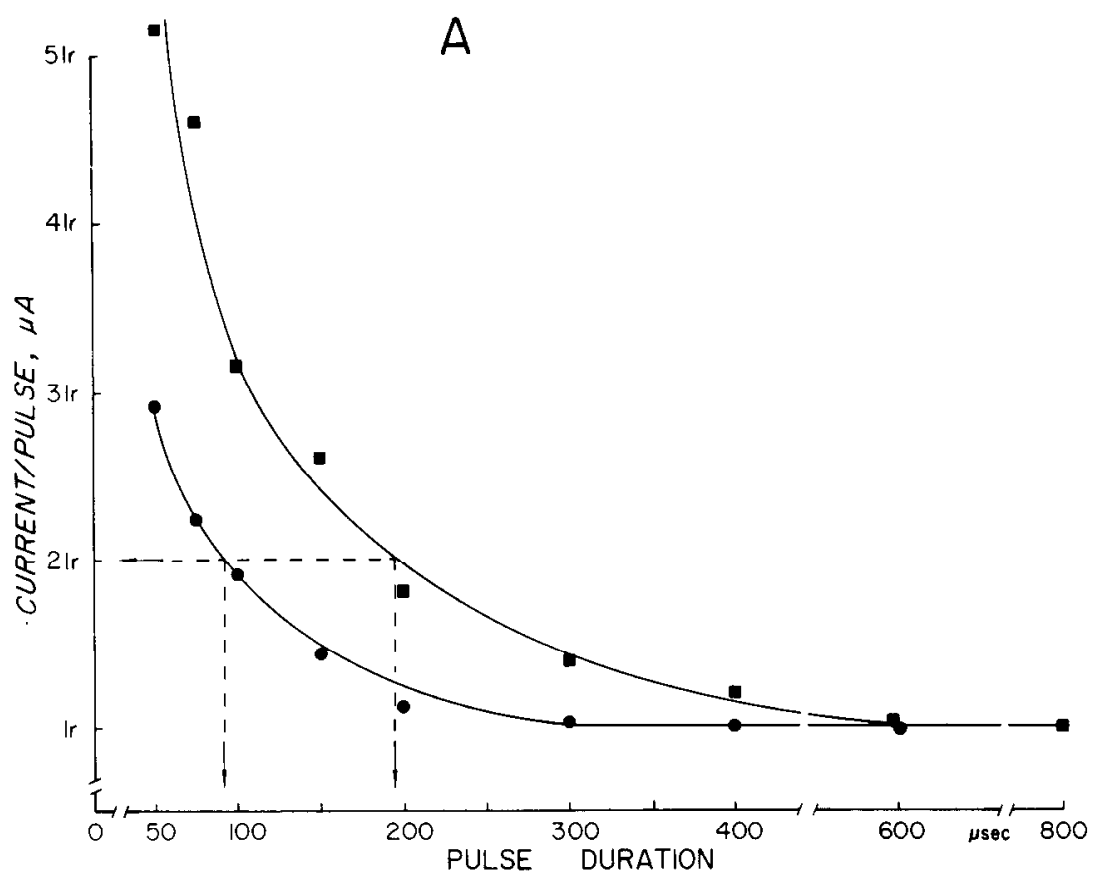

Figure 4. Strength-duration curves for stimulation in the caudal medulla with relatively small diameter $(50-70 \mu \mathrm{m}$ tips, $)$ and larger diameter (200 $\mu \mathrm{m}$ tips, $\square$ electrodes. $A$ is a linear and $B$ a log-log plot of the same data; each data point represents the mean of five $(\bullet)$ and two $(\square)$ experiments in seven different rats. The asymptotic minimum current to inhibit the TF reflex at long pulse durations (i.e., the rheobase current) was determined for each site of stimulation; the data in $A$ are portrayed as multiples of the rheobasic current $\left(I_{r}\right) . I_{r}$ 's (in $\mu$ A) for the two different diameter electrodes are shown in $B$. The chronaxies of stimulation for the two different diameter electrodes are (in $\mu \mathrm{sec}$ ) for $A, 92(0)$ and $190(\square)$; for $B$, $92(\bullet)$ and 195 (D). C. Sites of stimulation.
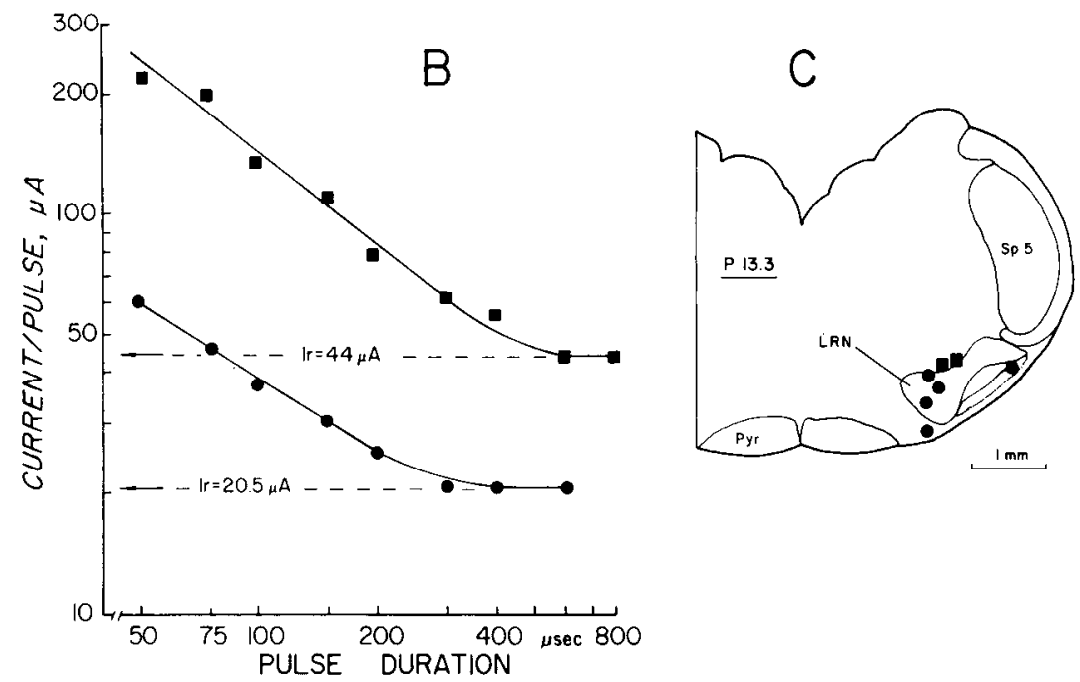

horn project to the LRN of the rat (Menetrey et al., 1983), a projection of potential importance to the rostral transmission of spinal nociccptive information. Thesc anatomical findings have recently been confirmed electrophysiologically by characterizing lumbar spinal cord neurons in the rat antidromically activated from the LRN (Menetrey et al., 1984a). The superficial laminae (I and II) of the spinal dorsal horn are characterized by terminations of small-diameter $\mathrm{A} \delta$ - and C-fiber primary afferents (Price and Dubner, 1977) and spinal interneurons in these laminae respond to noxious cutaneous stimuli (e.g., Cervero et al., 1976; Christensen and Perl, 1970; Menetrey et al., 1977). The potential importance of the LRN in the rat in pain mechanisms is emphasized by the relative paucity of projections of neurons in the superficial layers of the spinal dorsal horn to either the spinoreticular or spinothalamic tracts in the rat (spinoreticular: Chaouch et al., 1983; spinothalamic: Giesler et al., 1976, 1979, 1981; see also Menetrey et al., 1984b, for an electrophysiologic study of spinothalamic tract cells in the rat).

In addition to its well-established projections to the cerebellum, neurons in the LRN also have been reported to project to the midbrain periaqueductal gray in the rat (Marchand and Hagino, 1983) and the trigeminal nucleus caudalis (Senba et al.,
1981). The LRN, in turn, receives afferents from the periaqueductal gray (Rose, 1981; Roste et al., 1984), red nucleus (Qvist et al., 1984), and the A6 and A7 norcpinephrine-containing cell groups, the locus coerulus and Kölliker-Fuse nucleus (Rose, 1981). Focal electrical stimulation in these areas has been demonstrated as resulting in significant attenuation of spinal nociceptive reflexes (Jones and Gebhart, 1986; Sandkühler and Gebhart, 1984a) and/or spinal dorsal horn neuronal responses to noxious stimuli (e.g., Dostrovsky and Gray, 1982; Gebhart et al., 1983a; Hodge et al., 1981).

The present report establishes that sites requiring the lowest intensities of stimulation to inhibit the nociceptive TF reflex are localized in the LRN. Although slightly higher intensities of stimulation are required, inhibition of the TF reflex is produced even when stimulation in the LRN is initiated $2 \mathrm{sec}$ after heating of the tail has started, which suggests that the inhibition is instantaneous and temporal summation is not required. Unlike stimulation in the dorsolateral pons (Jones and Gebhart, 1986), the inhibitory effects of stimulation in the LRN do not outlast the period of stimulation. Stimulation-produced inhibition of the TF reflex is produced without significant effect on blood pressure. These data support recent results reported by Morton 


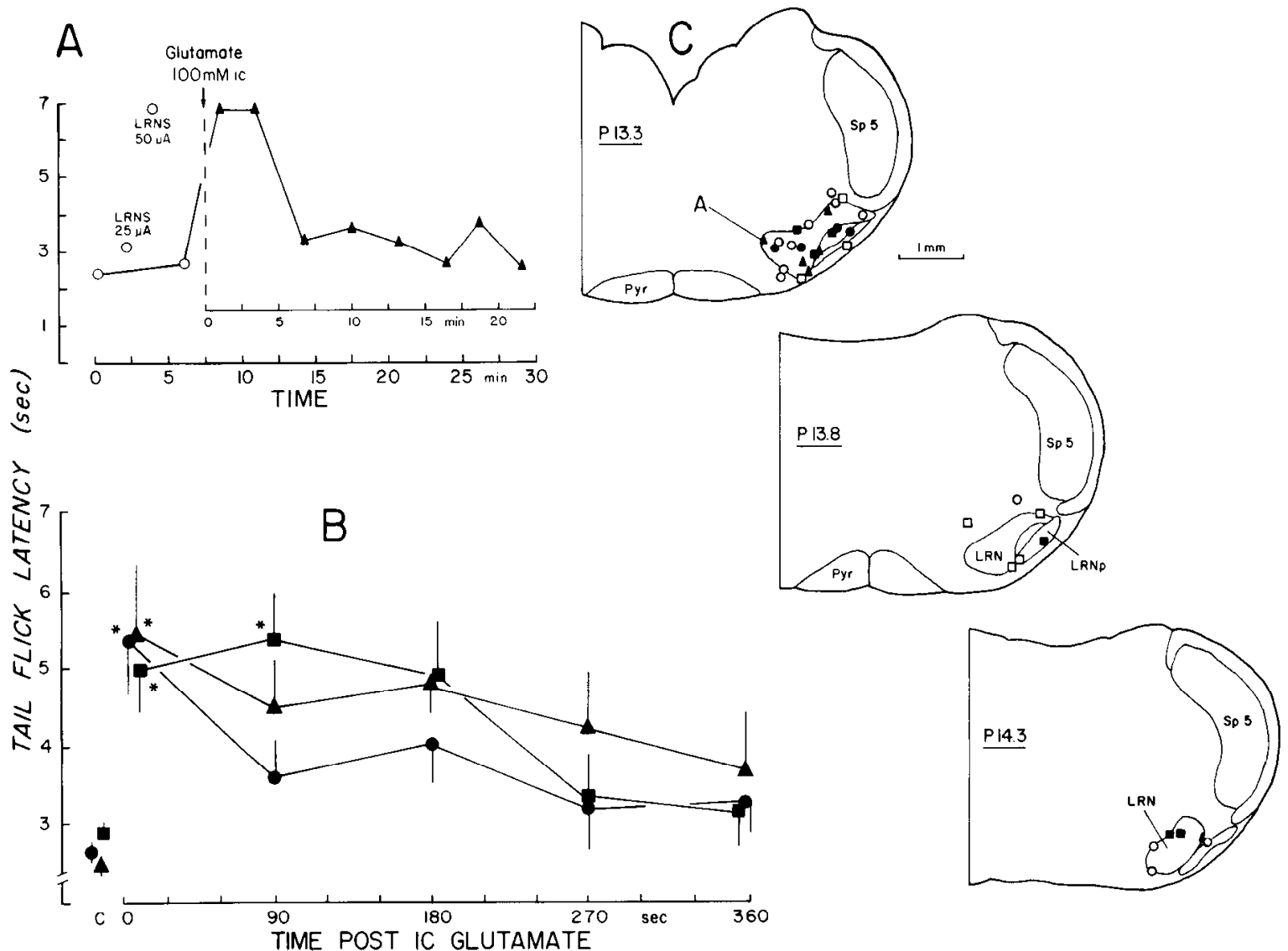

Figure 5. Effects of monosodium-S-glutamate (50-200 mM) microinjected intracerebrally (ic) in the caudal medulla on the TF latency. $A$, TF latency $(\mathrm{sec})$ is plotted against time ( $\mathrm{min})$ before and after the microinjection of S-glutamate ( $100 \mathrm{~mm} ; 0.5 \mu \mathrm{l})$. The intensity of LRNS for inhibition of the TF is indicated $(50 \mu \mathrm{A})$. S-glutamate was microinjected at the same site as stimulation (shown in $C$ ). $B$, Efficacy and duration of effect of 50,100 , and $200 \mathrm{~mm}$ S-glutamate microinjected in the LRN. *, Significantly different $(p \leq 0.05)$ from corresponding pre-glutamate control $(C)$ TF latencies (ANOVA followed by Dunnett's test). $C$, Sites of microinjection of S-glutamate indicated on representative coronal brain sections (Paxinos and Watson, 1982). Filled symbols, Sites where S-glutamate produced an inhibition of the TF reflex; open symbols, sites where no effect of S-glutamate on the TF reflex was observed. The symbols in $C$ correspond to those given in $A$ and $B$.

Table 1. Effect of intrathecally administered pharmacologic antagonists on the LRNS threshold to inhibit the TF reflex

\begin{tabular}{|c|c|c|c|c|c|c|}
\hline \multirow[b]{2}{*}{ Drug } & \multirow{2}{*}{$\begin{array}{l}\text { Dose } \\
(\mu \mathrm{g})\end{array}$} & \multirow[b]{2}{*}{$n$} & \multicolumn{3}{|c|}{ LRNS threshold $(\mu \mathrm{A})$} & \multirow{2}{*}{$\begin{array}{l}\text { Increase } \\
(\%)\end{array}$} \\
\hline & & & Pretreatment & Posttreatment & Change & \\
\hline \multirow[t]{2}{*}{ Naloxone } & 10 & 7 & $22.32 \pm 1.26$ & $26.79 \pm 4.03$ & $4.46 \pm 3.33$ & $19 \pm 14$ \\
\hline & 20 & 8 & $24.22 \pm 2.19$ & $27.34 \pm 3.53$ & $3.13 \pm 1.67$ & $11 \pm 6$ \\
\hline \multirow[t]{2}{*}{ Methysergide } & 15 & 3 & $25.00 \pm 7.22$ & $27.08 \pm 5.51$ & $2.08 \pm 2.08$ & $17 \pm 17$ \\
\hline & 30 & 10 & $22.50 \perp 2.67$ & $29.97 \pm 3.93^{*}$ & $7.48 \pm 3.06$ & $37 \pm 14$ \\
\hline \multirow[t]{2}{*}{ Phentolamine } & 15 & 5 & $23.75 \pm 3.64$ & $26.25 \pm 4.15$ & $2.50 \pm 1.53$ & $11 \pm 7$ \\
\hline & 30 & 10 & $23.13 \pm 2.64$ & $36.25 \pm 5.09^{*}$ & $13.11 \pm 3.54$ & $59 \pm 13$ \\
\hline \multirow[t]{2}{*}{ Prazosin } & 15 & 5 & $27.50 \pm 5.45$ & $30.00 \pm 5.00$ & $2.50 \pm 1.53$ & $14 \pm 10$ \\
\hline & 30 & 5 & $27.50 \pm 5.05$ & $30.00 \pm 5.00$ & $2.50 \pm 1.53$ & $14 \pm 10$ \\
\hline \multirow[t]{2}{*}{ Yohimbine } & 15 & 6 & $17.50 \pm 2.34$ & $28.75 \pm 5.80^{*}$ & $11.25 \pm 4.59$ & $62 \pm 24$ \\
\hline & 30 & 5 & $25.00 \pm 3.95$ & $47.92 \pm 8.01^{* *}$ & $22.92 \pm 5.31$ & $94 \pm 26$ \\
\hline Propranolol & 10 & 6 & $17.71 \pm 1.04$ & $18.75 \pm 1.61$ & $1.04 \pm 1.04$ & $6 \pm 6$ \\
\hline Haloperidol & 10 & 6 & $17.71 \pm 1.92$ & $19.79 \pm 2.51$ & $2.08 \pm 1.32$ & $12 \pm 8$ \\
\hline Atropine & 4 & 4 & $18.75 \pm 0$ & $26.56 \pm 7.81$ & $7.81 \pm 7.81$ & $42 \pm 42$ \\
\hline D-Pro ${ }^{2}, \mathrm{D}-\mathrm{Phe}^{7}$, & 15 & 3 & $16.67 \pm 2.36$ & $16.67 \pm 2.36$ & $0 \pm 0$ & $0 \pm 0$ \\
\hline D-Trp ${ }^{9}$, substance $P$ & 30 & 4 & $23.44+1.56$ & $23.44+3.93$ & $0+2.55$ & $0 \pm 12$ \\
\hline
\end{tabular}

${ }^{*} p \leq 0.05$ and ${ }^{* *} p \leq 0.01$; significantly different from the pretreatment LRNS threshold (Student's paired $t$ test). 


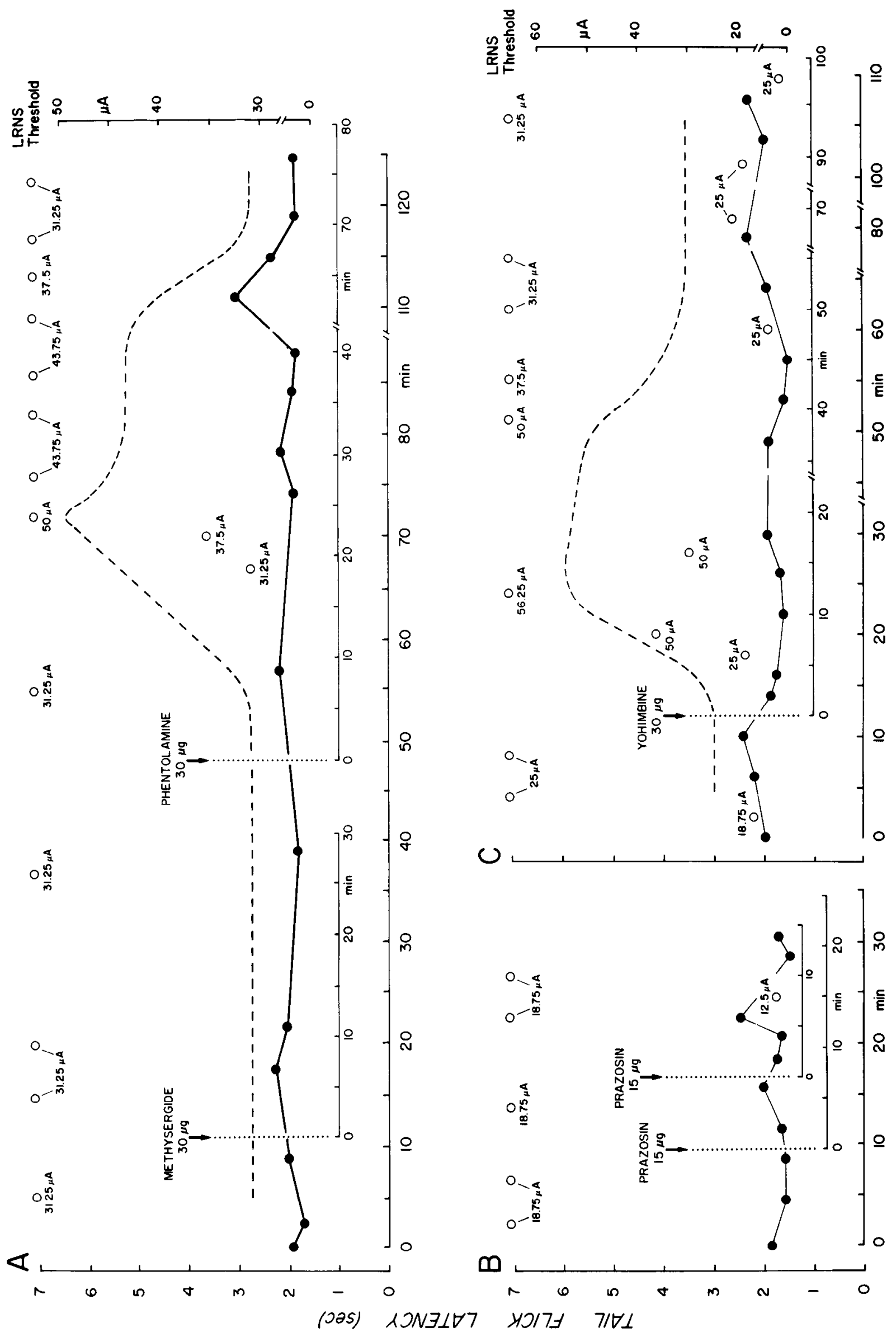





Figure 7. Summary of the effects of five different antagonists administered intrathecally on the stimulation thresholds in the LRN required to inhibit the TF reflex. Mean percentage increases $( \pm$ SEM) in the stimulation threshold for cumulative doses of intrathecally administered antagonists are indicated, as are the sites of stimulation in the LRN. *, Significantly different (see Table 1) from pretreatment LRN stimulation thresholds.

et al. (1983), who determined that the excitation of spinal dorsal horn interneurons in the cat produced by activation of unmyelinated primary afferents (C-fibers) was selectively inhibited by stimulation in the LRN. Electrical stimulation in brain invariably excites fibers of passage as well as cell bodies. Morton et al. (1983) stimulated medially, dorsally, and rostrally to the LRN and observed the effects to be limited, which suggests that the inhibition was the result of activation of cell bodies in the LRN. In related studies, Hall et al. (1982) introduced lesions into areas medial and rostral to the LRN without observing an effect on tonic descending inhibition of spinal dorsal horn neurons; they concluded that cell bodies in the LRN, and not descending fibers from another area, represent the brain stem source of neurons responsible for tonic descending inhibition. In the rat, the area surrounding the LRN contains fibers of all of the main ascending spinal tracts (Menetrey et al., 1983), and it is thus possible that the inhibition produced by LRNS in this report could arise from activation of ascending fibers to the medial brain stem (for example). The results of the systematic tracking experiments in this report support the conclusion that activation of cell bodies in the LRN is responsible for the inhibitory effects observed. Unlike stimulation in the rostral medulla (Dostrovsky et al., 1982; Sandkühler and Gebhart, 1984a; Zorman et al., 1981), pons (Jones and Gebhart, 1986) or midbrain (Dostrovsky et al., 1982; Sandkühler and Gebhart, 1984a), the area in the caudal medulla from which descending inhibition was produced was relatively small and confined to the LRN and immediately adjacent tissue. Moreover, strength-duration characterization of stimulation in the LRN and inhibition of the TF reflex following the microinjection of glutamate both indicate that the descending inhibition produced by stimulation in the LRN is the result of activation of cell bodies.

In an earlier report (Hall et al., 1982), the LRN was reported to be the source of tonic descending inhibition of dorsal horn neurons in the cat, and it was suggested that catecholamines may be the spinal neurotransmitter responsible for the tonic modulation of spinal dorsal horn neurons. Several studies have recently demonstrated that spinal catecholaminergic terminals are likely to be tonically active, as revealed by administration of noradrenergic antagonists into the spinal subarachnoid space (e.g., Sagen and Proudfit, 1984). In this and another study (Jones and Gebhart, 1986), the intrathecal administration of $\alpha$-adrenoceptor antagonists resulted in a significant decrease in the TF latency, suggesting removal of a supraspinal tonic (nor)adrenergic influence. Further, the intrathecal administration of the nonselective $\alpha$-adrenoceptor antagonist phentolamine and the selective $\alpha_{2}$-antagonist yohimbine significantly increased the stimulation threshold in the LRN to inhibit the TF reflex, establishing the (nor)adrenergic nature of LRNS.

A variety of possible spinal neurotransmitter candidates were examined in this study. There exists a spinopetal enkephalinergic pathway originating near the LRN (Hökfelt et al., 1979)

$\leftarrow$

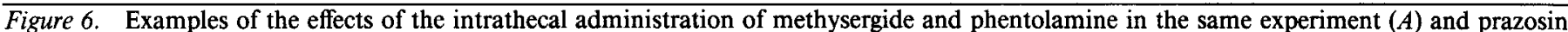

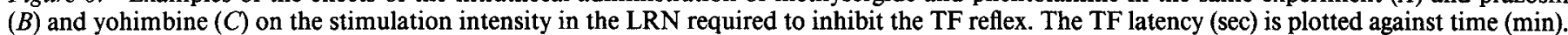

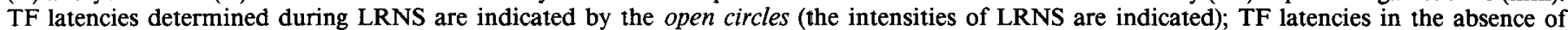

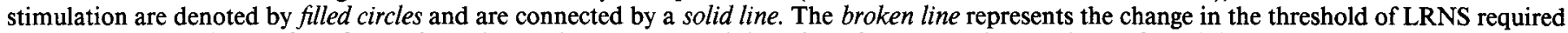

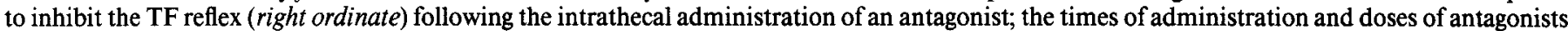

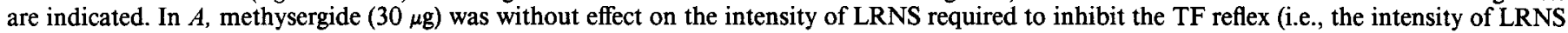

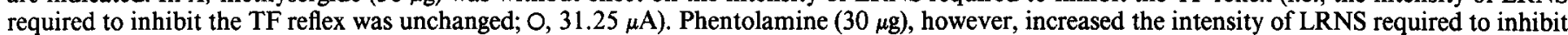

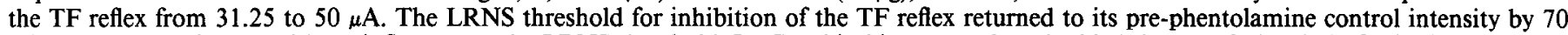

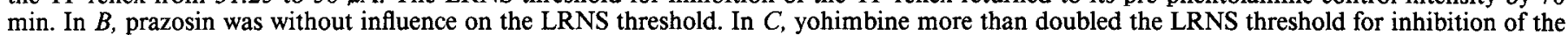
TF reflex. 
Table 2. Effect of intrathecally administered pharmacologic antagonists on TF latency

\begin{tabular}{|c|c|c|c|c|c|c|}
\hline \multirow[b]{2}{*}{ Drug } & \multirow{2}{*}{$\begin{array}{l}\text { Dose } \\
(\mu \mathrm{g})\end{array}$} & \multirow[b]{2}{*}{$n$} & \multicolumn{3}{|c|}{ TF latency (sec) } & \multirow{2}{*}{$\begin{array}{c}\text { Change } \\
(\%)\end{array}$} \\
\hline & & & Pretreatment & Posttreatment & Change & \\
\hline \multirow[t]{2}{*}{ Naloxone } & 10 & 7 & $2.62 \pm 0.23$ & $2.82+0.33$ & $0.21+0.18$ & $7 \pm 7$ \\
\hline & 20 & 8 & $2.51 \pm 0.18$ & $2.78 \pm 0.30$ & $0.27 \pm 0.20$ & $10 \pm 7$ \\
\hline \multirow[t]{2}{*}{ Methysergide } & 15 & 3 & $2.84 \pm 0.22$ & $3.91 \pm 0.91$ & $1.07 \pm 0.81$ & $37 \pm 26$ \\
\hline & 30 & 10 & $2.56 \pm 0.17$ & $2.56 \pm 0.24$ & $0.01 \pm 0.18$ & $0 \pm 6$ \\
\hline \multirow[t]{2}{*}{ Phentolamine } & 15 & 5 & $2.66 \pm 0.07$ & $2.91 \pm 0.91$ & $0.24 \pm 0.22$ & $10 \pm 8$ \\
\hline & 30 & 10 & $2.79 \pm 0.24$ & $2.10 \pm 0.16^{*}$ & $-0.69 \pm 0.29$ & $-20 \pm 8$ \\
\hline \multirow[t]{2}{*}{ Prazosin } & 15 & 5 & $1.93 \pm 0.30$ & $1.98 \pm 0.21$ & $0.06 \pm 0.23$ & $7 \pm 12$ \\
\hline & 30 & 5 & $1.97 \pm 0.29$ & $2.23 \pm 0.38$ & $0.24 \pm 0.56$ & $23 \pm 29$ \\
\hline \multirow[t]{2}{*}{ Yohimbine } & 15 & 6 & $2.25 \pm 0.23$ & $2.04 \pm 0.27$ & $-0.21 \pm 0.44$ & $-3 \pm 20$ \\
\hline & 30 & 5 & $2.11 \pm 0.17$ & $1.59 \pm 0.09^{*}$ & $-0.52 \pm 0.22$ & $-22 \pm 7$ \\
\hline Propranolol & 10 & 6 & $2.02 \pm 0.05$ & $2.44 \pm 0.18$ & $0.42 \pm 0.20$ & $21 \pm 10$ \\
\hline Haloperidol & 10 & 6 & $2.33 \pm 0.22$ & $2.58 \pm 0.38$ & $0.24 \pm 0.31$ & $10 \pm 12$ \\
\hline Atropine & 4 & 4 & $1.96 \pm 0.07$ & $2.14 \pm 0.28$ & $0.18 \pm 0.22$ & $8 \pm 11$ \\
\hline D-Pro ${ }^{2}$, D-Phe?, & 15 & 5 & $2.29 \pm 0.20$ & $4.06 \pm 1.20$ & $1.77 \pm 1.12$ & $73 \pm 45$ \\
\hline D-Trp ${ }^{9}$, substance $P$ & 30 & 5 & $1.96 \pm 0.14$ & $4.00 \pm 1.23$ & $2.04 \pm 1.18$ & $101 \pm 55$ \\
\hline
\end{tabular}

${ }^{*} p \leq 0.05$; significantly different from the pretreatment TF latency (Student's paired $t$ test).

and both enkephalin- and dynorphin-containing cell bodies are present in the LRN of the rat (Khachaturian et al., 1982, 1983). Naloxone administered intrathecally had no effect on the stimulation threshold in the LRN for inhibition of the TF reflex. A substance P-like immunoreactive material is released in rat spinal cord superfusate by kainic acid microinjected into the area of the LRN (Takano et al., 1984). It has been reported that the intrathecal administration of substance $P$ depresses the TF reflex in the rat in a dose-related fashion (Doi and Jurna, 1981) and also depresses spinal motor and sensory responses to stimulation of nociceptive afferents (Doi and Jurna, 1982). The putative substance $\mathrm{P}$ antagonist employed here failed to affect the stimulation threshold in the LRN but did itself completely block the TF reflex in four of 10 rats. Similar results following the intrathecal administration of substance $P$ antagonists have been reported (Salt and Hill, 1983), and there is somc qucstion whether many of these substance $P$ antagonists may not also be partial agonists. In four of 10 animals, intrathecally administered methysergide increased, by $50 \%$ or more, the stimulation threshold in the LRN for inhibition of the TF reflex. There are, however, few serotonin-containing cell bodies in or near the LRN, and the effect of methysergide observed likely arose from activation of descending serotonergic fibers passing through or near the LRN or from activation of cells in the LRN that project to relatively rostral midline raphe nuclei. Although methysergide has been used widely and successfully as a serotonergic antagonist when given intrathecally in the spinal cord (e.g., Schmauss et al., 1983), there is a question about its efficacy as an antagonist at serotonergic receptors in the CNS (Aghajanian et al., 1975). Electrophysiologic and pharmacologic studies indicate that there exists a heterogeneity of receptors for serotonin (5-HT) (Snyder and Peroutka, 1980). Evidence to date, however, suggests that only the $5-\mathrm{HT}_{1}$ receptor is present in rat spinal cord (Blackshear et al., 1981; Monroe and Smith, 1983), and thus the relative nonselectivity of methysergide for $5-\mathrm{HT}_{1}$ and $5-\mathrm{HT}_{2}$ receptors is not at issue. However, it is possible that the relatively high dose of methysergide $(30 \mu \mathrm{g})$ used here also affected spinal adrenoceptors. The results from this study were variable following the intrathecal administration of methysergide, and the extent to which stimulation in the LRN affects directly descending serotonergic systems remains unclear. There also exist AChE-containing cells in the caudal medulla near the LRN (Butcher and Woolf, 1982), and cholinoceptive mechanisms have recently been established as activating centrifugal pathways of inhibition (Katayama et al., 1984). Atropine failed to affect the LRNS threshold, however. Thus, possible enkephalinergic, cholinergic, and substance $P$ spinopetal projections arising in the caudal medulla apparently do not contribute to the descending inhibition produced from the LRN. A spinopetal (nor)adrenergic $\alpha_{2}$-adrenoceptor-mediated pathway is implicated, since neither halopcridol, propranolol, nor the $\alpha_{1}$-sclective adrenoceptor antagonist prazosin affected the threshold in the LRN for inhibition of the TF reflex.

Although these data clearly indicate that activation of cell bodies in the LRN is responsible for the $\alpha_{2}$-adrenoceptor-mediated inhibition of the TF reflex observed, it is unclear whether the LRN is the source of the spinopetal catecholaminergic pathway associated with descending inhibition from the LRN. There exist both norepinephrine- and epinephrine-containing cell groups in the caudal medulla near the LRN, designated A1 (norepinephrine) and $\mathrm{Cl}$ (epinephrine). The early histofluorescence studies of Dahlström and Fuxe (1965) and an immunohistochemical study by Hökfelt et al. (1974) indicated that neurons in both areas send axons to the spinal cord in the rat. The A1 cell group lies in closest approximation to the LRN; A1 neurons are present and overlie diffusely the rostrocaudal extent of the LRN, clustering dorsally and laterally over the caudal LRN (Palkovits and Jacobowitz, 1974). The composite map in Figure 3 reveals that the lowest thresholds for inhibition of the TF reflex (i.e., 12.5-25 $\mu \mathrm{A}$ ) are associated with stimulation sites in the dorsolateral, caudal LRN. The C1 epinephrine-containing neurons occupy a position similar to $\mathrm{A} 1$ neurons relative to the LRN but are more concentrated rostral to the LRN and are a rostral extension of the A1 group (Ross et al., 1984). Thus, stimulation in the LRN likely affects both catecholamine-containing cell groups and/or their descending fibers.

Neurons in $\mathrm{Cl}$ project to the spinal cord in the rat, but apparently only to the intermediolateral cell column in the thoracic spinal cord, and it has been proposed that $\mathrm{C} 1$ neurons comprise the tonic vasomotor center of the brain stem (Ross et al., 1984). 
Focal electrical stimulation in the $\mathrm{Cl}$ region at intensities and parameters of stimulation nearly identical to those employed here produces pressor effects as great as $100 \mathrm{mmHg}$ (Reis et al., 1984). Since blood pressure changed little or not at all after LRN stimulation (see Fig. 3), it is unlikely that the descending inhibition produced arose from activation of epinephrine-containing cells in the more rostral $\mathrm{C} 1$ group. The A1 group, however, also may not mediate the descending, adrenoceptor-mediated inhibition of the TF reflex from the LRN. While electrophysiologic, biochemical, and anatomic studies indicate that axons of neurons in the Al group descend the spinal cord in the rat (Fleetwood-Walker et al., 1983; Satoh et al., 1977), rabbit (Blessing et al., 1981), and cat (Fleetwood-Walker and Coote, 1981), recent reports suggest that spinal projections from the Al group in the rat are minor or nonexistent (Loewy and McKellar, 1980; Westlund et al., 1983). Rather, projections of A1 neurons are rostral to the hypothalamus (Blessing et al., 1981; Sawchenko and Swanson, 1982). Moreover, it has been reported that fibers from the Al region that do descend the spinal cord are non-noradrenergic (Björklund and Skagerberg, 1982). Thus, although strength-duration characterization of LRNS and the microinjection of S-glutamate into the LRN indicate that activation of cell bodies produces a spinal $\alpha_{2}$-adrenoceptor-mediated inhibition of the TF reflex, anatomical studies suggest, contrariwise, that neither the catecholamine-containing $\mathrm{Al}$ nor $\mathrm{Cl}$ groups in the caudal medulla contribute to the results reported here.

Other candidate catecholamine-containing cell groups include the more rostral A7, A6 (locus coeruleus/subcoeruleus) and A5 groups. Axons of neurons in the A5 group descend the cord to the intermediolateral column in the rat (Byrum et al., 1984; Loewy et al., 1979), and Guyenet (1984) has recently demonstrated the potential role of the A5 group in arterial baroreceptor reflexes. However, a significant proportion of retrogradely labeled neurons in the pontine A5 cell group is also noncatecholaminergic (Björklund and Skagerberg, 1982). The coeruleospinal noradrenergic pathway is well defined in that rat, terminating principally in the ventral horn of the spinal cord, but also innervating the intermediate gray and dorsal horn (Björklund and Skagerberg, 1982). Spinopetal projections originating in the pontine $A 7$ and $A 6$ cell groups traverse the brain stem in the vicinity of the A1 cell group as they descend to the spinal cord (Saper and Loewy, 1980; Westlund and Coulter, 1980). While this report establishes that the neural elements affected by stimulation inhibiting the TF reflex include cell bodies in the LRN, stimulation in the brain must also affect fibers of passage, and it is conceivable that the $\alpha_{2}$-adrenoceptor-mediated descending inhibition reported here arises from activation of these descending fibers. In this regard, it is noteworthy that phentolamine and yohimbine never fully blocked the inhibitory effect of LRNS. As current intensity was increased, thus increasing the area of neural tissue affected by electrical stimulation, the TF was inhibited. Further, focal electrical stimulation in the A6 area in the rat produces an antinociception (Margalit and Segal, 1979; Segal and Sandberg, 1977), increases the spinal content of noradrenergic metabolites (Crawley et al., 1979), and inhibits both nociceptive spinal dorsal horn neurons (Hodge et al., 1981) and the nociceptive TF reflex (Jones and Gebhart, 1986). Moreover, characterization of locus coeruleusproduced inhibition of the TF reflex reveals that it also is mediated by $\alpha_{2}$-adrenoceptors in the spinal cord (Jones and Gebhart, 1986). Thus, while stimulation certainly influences cell bodies in the LRN, the $\alpha_{2}$-mediated descending inhibition produced by LRNS may reflect also an effect of stimulation of descending noradrenergic fibers from norepinephrine-containing cell bodies rostral to the Al group. The failure to block LRNS completely with pharmacologic antagonists administered intrathecally may reflect activation by LRNS of cell bodies in the LRN that contain a transmitter other than norepinephrine.
In summary, these data establish the LRN in the caudal medulla to be an area from which the nociceptive TF reflex can be inhibited at low intensities of focal electrical stimulation. Areas adjacent to the LRN require higher intensities of stimulation to activate descending inhibition of the TF reflex, probably reflecting current spread to the LRN. Strength-duration characterization of stimulation and the microinjection of glutamate into the LRN at the same site where electrical stimulation was effective suggests that the descending inhibition produced by electrical stimulation arises from activation of cell bodies in the LRN. Finally, the intrathecal administration of a variety of pharmacological antagonists revealed the descending inhibition produced by stimulation in the LRN to be mediated by spinal $\alpha_{2}$-adrenoceptors.

\section{References}

Aghajanian, G. K., H. J. Haigler, and J. L. Bennett (1975) Amine receptors in CNS. III. 5-hydroxytryptamine in brain. In Handbook of Psychopharmacology, L. Iversen and S. Iversen, eds., pp. 63-96, Plenum, New York.

Beitz, A. J., M. A. Mullett, and L. L. Weiner (1983) The periaqueductal gray projections to the rat spinal trigeminal, raphe magnus, gigantocellular pars alpha and paragigantocellular nuclei arise from separate neurons. Brain Res. 288: 307-314.

Björklund, A., and G. Skagerberg (1982) Descending monoaminergic projections to the spinal cord. In Brain Stem Control of Spinal Mechanisms, B. Sjölund and A. Björklund, eds., pp. 55-88, Elsevier, Amsterdam.

Blackshear, M. A., L. R. Steranka, and E. Sanders-Bush (1981) Multiple serotonin receptors: regional distribution and effect of raphe lesions. Eur. J. Pharmacol. 76: 325-334.

Blessing, W. W., A. K. Goodchild, R. A. L. Dampney, and J. P. Chalmers. (1981) Cell groups in the lower brain stem of the rabbit projecting to the spinal cord, with special reference to catecholaminecontaining neurons. Brain Res. 221: 35-55.

Butcher, L. L., and M. J. Woolf (1982) Cholinergic and serotonergic systems in the brain and spinal cord: Anatomic organization, role in intercellular communication processes, and interactive mechanisms. In Chemical Transmission in the Brain, R. M. Buijs, P. Pevet, and D. F. Swaab, eds., pp. 3-40, Elsevier, Amsterdam.

Byrum, C. E., R. L. Stornetta, and P. G. Guyenet (1984) Electrophysiological properties of spinally-projecting A5 noradrenergic neurons. Brain Res. 303: 15-29.

Carstens, E. (1982) Inhibition of spinal dorsal horn neuronal responses to noxious skin heating by medial hypothalamic stimulation in the cat. J. Neurophysiol. 41: 808-822.

Carstens, E., D. Klumpp, and M. Zimmermann (1980) Differential inhibitory effects of medial and lateral midbrain stimulation on spinal neuronal discharges to noxious skin heating in the cat. J. Neurophysiol. 43: 332-342.

Carstens, E., J. D. MacKinnon, and M. J. Guinan (1982) Inhibition of spinal dorsal hom neuronal responses to noxious skin heating by medial preoptic and septal stimulation in the cat. J. Neurophysiol. 48: 981-991.

Cervero, F., A. Iggo, and H. Ogawa (1976) Nociceptor-driven dorsal horn neurons in the lumbar spinal cord of the cat. Pain 2: 5-24.

Chaouch, A., D. Menetrey, D. Binder, and J. M. Besson (1983) Neurons at the origin of the medial component of the bulbo-pontine spinoreticular tract in the rat. An anatomical study using horseradish peroxidase retrograde transport. J. Comp. Neurol. 214: 309-320.

Christensen, B. N., and E. R. Perl (1970) Spinal neurons specifically excited by noxious or thermal stimuli: The marginal zone of the dorsal horn. J. Neurophysiol. 33: 293-307.

Crawley, J. N., R. H. Roth, and J. W. Mass (1979) Locus coeruleus stimulation increases noradrenergic metabolite levels in rat spinal cord. Brain Res. 166: 180-184.

Dahlström, E., and K. Fuxe (1965) Evidence for the existence for monoamine neurons in the central nervous system. II: Experimental induced changes in the intraneuronal amine levels of the bulbospinal neuron systems. Acta Physiol. Scand. 64 (Suppl. 247): 1-36.

De Sousa, B. N., and L. A. Horrocks (1979) Development of rat spinal cord. I. Weight and length with a method for rapid removal. Dev. Neurosci. 2: 115-121. 
Dietrichs, E., and F. Walberg (1979) The cerebellar projection from the lateral reticular nucleus as studied with retrograde transport of horseradish peroxidase. Anat. Embryol. 155: 273-290.

Doi, T., and I. Jurna (1981) Intrathecal substance $P$ depresses the tailflick response-antagonism by naloxone. Naunyn Schmiedebergs Arch. Pharmacol. 317: 135-139.

Doi, T., and I. Jurna (1982) Intrathecal substance P depresses spinal motor and sensory responses to stimulation of nociceptive afferentsantagonism by naloxone. Naunyn Schmiedebergs Arch. Pharmacol. 319: 154-160.

Dostrovsky, J. O., and B. G. Gray (1982) Modulation of the somatosensory responses of spinal cord dorsal horn neurons in the cat by electrical stimulation in the red nucleus. Neurosci. Abstr. 8: 91 .

Dostrovsky, J. O., J. W. Hu, B. J. Sessle, and R. Sumino (1982) Stimulation sites in periaqueductal gray, nucleus raphe magnus and adjacent regions effective in suppressing oral facial reflexes. Brain Res. 252: 287-297.

Fields, H. L., A. I. Basbaum, C. H. Clanton, and S. D. Anderson (1977) Nucleus raphe magnus inhibition of spinal cord dorsal horn neurons. Brain Res. 126: 441-453.

Fields, H. L., J. Bry, I. Hentall, and G. Zorman (1983) The activity of neurons in the rostral medulla of the rat during withdrawal from noxious heat. I. Neurosci. 3: 2545-2552.

Fleetwood-Walker, S. M., and J. H. Coote (1981) The contribution of brain stem catecholamine cell groups to the innervation of the sympathetic lateral cell column. Brain Res. 205: 141-155.

Fleetwood-Walker, S. M., J. H. Coote, and M. P. Gilbey (1983) Identification of spinally projecting neurons in the Al catecholamine cell group of the ventrolateral medulla. Brain Res. 273: 25-33.

Gebhart, G. F. (1985) Modulatory effects of descending systems on spinal dorsal horn neurons. In Spinal Afferent Processing, T. L. Yaksh, ed., pp. 391-416, Plenum, New York.

Gebhart, G. F., and M. H. Ossipov (1984) Inhibition of spinal nociceptive tail-flick (TF) reflex from the lateral reticular nucleus (LRN) is mediated by spinal $\alpha_{2}$-adrenergic receptors. Neurosci. Abstr. 10: 98.

Gebhart, G. F., J. Sandkühler, I. G. Thalhammer, and M. Zimmermann (1983a) Quantitative comparison of inhibition in spinal cord of nociceptive information by stimulation in periaqueductal gray or nucleus raphe magnus of the cat. J. Neurophysiol. 50: 433-445.

Gebhart, G. F., J. Sandkühler, J. G. Thalhammer, and M. Zimmerman (1983b) Inhibition of spinal nociceptive information by stimulation in midbrain of the cat is blocked by lidocaine microinjected in nucleus raphe magnus and medullary reticular formation. J. Neurophysiol. 50: 446-459.

Giesler, G. J., Jr., D. Menetrey, G. Guilbaud, and J. M. Besson (1976) Lumbar cord neurons at the origin of the spinothalamic tract in the rat. Brain Res. 118: 320-324.

Giesler, G. J., Jr., D. Menetrey, and A. I. Basbaum (1979) Differential origin of spinothalamic tract projections to medial and lateral thalamus in the rat. J. Comp. Neurol. 184: 107-126.

Giesler, G. F., Jr., H. R. Spiel, and W. D. Willis (1981) Organization of spinothalamic tract axons within the rat spinal cord. J. Comp. Neurol. 195: 243-252.

Goodchild A. K., R. A. L. Dampney, and R. Bandler (1982) A method for evoking physiological responses by stimulation of cell bodies, but not axons of passage, within localized regions of the central nervous system. J. Neurosci. Methods 6: 351-363.

Guyenet, P. G. (1984) Baroreceptor-mediated inhibition of A5 noradrenergic neurons. Brain Res. 303: 31-40.

Hall, J. G., A. W. Duggan, C. R. Morton, and S. M. Johnson (1982) The location of brain stem neurons tonically inhibiting dorsal horn neurons of the cat. Brain Res. 244: 215-222.

Hodge, C. J., A. B. Apkarian, R. T. Stevens, G. D. Vogelsang, and H. J. Wisnicki (1981) Locus coeruleus modulation of dorsal horn unit responses to cutaneous stimulation. Brain Res. 240: 415-420.

Hökfelt, T., K. Fuxe, M. Goldstein, and O. Johansson (1974) Immunohistochemical evidence for the existence of adrenaline neurons in rat brain. Brain Res. 66: 235-251.

Hökfelt, T., T. Terenius, H. G. J. M. Kuypers, and O. Dann (1979) Evidence for enkephalin immunorcactive ncurons in the medulla oblongata projecting to the spinal cord. Neurosci. Lett. 14: 55-60.

Johnson, J. L. (1972) Glutamic acid as a synaptic transmitter in the nervous system. A review. Brain Res. 37: 1-19.

Jones, S. L., and G. F. Gebhart (1986) Characterization of coeruleo- spinal inhibition of the nociceptive tail-flick reflex in the rat: Mediation by spinal $\alpha_{2}$ adrenoceptors. Brain Res. (in press).

Katayama, Y., D. S. DeWitt, D. P. Becker, and R. L. Hayes (1984) Behavioral evidence for a cholinoceptive pontine inhibitory area: Descending control of spinal motor output and sensory input. Brain Res. 296: 241-262.

Khachaturian, H., S. J. Watson, M. E. Lewis, D. Coy, A. Goldstein, and H. Akil (1982) Dynorphin immunocytochemistry in the rat central nervous system. Peptides 3: 941-954.

Khachaturian, H., M. E. Lewis, and S. J. Watson (1983) Enkephaline systems in diencephalon and brainstem of the rat. J. Comp. Neurol. 220: $310-320$.

Künzle, H. (1973) Autoradiographic tracing of the cerebellar projection from the lateral reticular nucleus in the cat. Exp. Brain Res. 22; 255-266.

Liebeskind, J. C., G. Guilbaud, J. M. Besson, and J. L. Oliveras (1973) Analgesia from electrical stimulation of the periaqueductal gray matter in the cat: Behavioral observations and inhibitory effects on spinal cord interneurons. Brain Res. 50:441-446.

Loewy, A. D., and S. McKellar (1980) The neuroanatomical basis of central cardiovascular control. Fed. Proc. 39: 2495-2503.

Loewy, A. D., S. McKellar, and C. B. Saper (1979) Direct projections from the A5 catecholamine cell group to the intermediolateral cell column. Brain Res. 174: 309-314.

Marchand, J. E., and N. Hagino (1983) Afferents to the periaqueductal gray in the rat. A horseradish peroxidase study. Neuroscience 9:95106.

Margalit, D., and M. Segal (1979) A pharmacologic study of analgesia produced by stimulation in the nucleus locus coeruleus. Psychopharmacology 62: 169-173.

Menetrey, D., G. J. Giesler, Jr., and J. M. Besson (1977) An analysis of response properties of spinal cord dorsal horn neurons to nonnoxious and noxious stimuli in the spinal rat. Exp. Brain Res. 27: $15-33$.

Menetrey, D., A. Chaouch, D. Binder, and J. M. Besson (1982) Neurons at the origin of the spinomesenchephalic tract in the rat: An anatomical study using the retrograde transport of horseradish peroxidase. J. Comp. Neurol. 206: 193-207.

Menetrey, D., F. Roudier, and J. M. Besson (1983) Spinal neurons reaching the lateral reticular nucleus as studied in the rat by retrograde transport of horseradish peroxidase. J. Comp. Neurol. 220:439-452.

Menetrey, D., J. de Pommery, and J. M. Besson (1984a) Electrophysiological characteristics of lumbar spinal neurons backfired from the lateral reticular nucleus in the rat. J. Neurophysiol. 52: 595-611.

Menetrey, D., J. de Pommery, and F. Roudier (1984b) Properties of deep spinothalamic tract cells in the rat, with special reference to ventromedial zone of lumbar dorsal horn. J. Neurophysiol. 612-624.

Monroe, P. J., and D. J. Smith (1983) Characterization of multiple $\left[{ }^{3} \mathrm{H}\right] 5$-hydroxytryptamine binding sites in rat spinal cord tissue. $\mathrm{J}$. Neurochem. 41: 349-355.

Morton, C. R., S. M. Johnson, and A. W. Duggan (1983) Lateral reticular regions and the descending control of dorsal horn neurons of the cat: Selective inhibition by electrical stimulation. Brain Res. 275: 13-21.

Morton, C. R., A. W. Duggan, and Z. Q. Zhao (1984) The effects of lesions of medullary midline and lateral reticular areas on inhibition in the dorsal horn produced by periaqueductal gray stimulation in the cat. Brain Res. 301: 121-130.

Ossipov, M. H., and G. F. Gebhart (1984) Inhibition of the spinal nociceptive tail flick (TF) reflex from the medullary lateral reticular nucleus (LRN). Fed. Proc. 43: 994.

Palkovits, M., and D. M. Jacobowitz (1974) Topographic atlas of catecholamine and acetylcholinesterase-containing neurons in the rat brain. II. Hindbrain (mesencephalon, rhombencephalon). J. Comp. Neurol. 157: 29-41.

Paxinos, G., and C. Watson (1982) The Rat Brain in Stereotaxic Coordinates, Academic, New York.

Price, D. D., and R. Dubner (1977) Neurons that subserve the sensorydiscriminative aspects of pain. Pain 3: 307-338.

Puil, E. (1982) S-Glutamate: Its interaction with spinal neurons. Brain Res. Rev. 3: 229-332.

Qvist, H., E. Dietrichs, and F. Walberg (1984) The projection from the red nucleus to the lateral reticular nucleus is bilateral. Neurosci. Lett. (Suppl.) 18: S57.

Reis, D. J., A. R. Granata, T. H. Joh, C. A. Ross, D. A. Ruggiero, and 
D. H. Park (1984) Brain stem catecholamine mechanisms in tonic and reflex control of blood pressure. Hypertension 6 (Suppl. II): II-7-II-15.

Rose, J. D. (1981) Projections to the caudolateral medulla from the pons, midbrain and diencephalon in the cat. Exp. Neurol. 72: 413428.

Ross, C. A., D. A. Ruggiero, T. H. Joh, D. H. Park, and D. J. Reis (1984) Rostral ventrolateral medulla: Selective projections to the thoracic autonomic cell column from the region containing $\mathrm{Cl}$ adrenaline neurons. J. Comp. Neurol. 228: 168-185.

Roste, L. S., E. Dietrichs, and F. Walberg (1984) A projection from the periaqueductal gray to the lateral reticular nucleus in the cat. Neurosci. Lett. (Suppl.) 18: S57.

Sagen, J., and H. K. Proudfit (1984) Effect of intrathecally administered noradrenergic antagonists on nociception in the rat. Brain Res. 310: 295-301.

Salt, T. E., and R. G. Hill (1983) Neurotransmitter candidates of somatoscnsory primary afferent fibers. Neuroscience 10: 1083-1104.

Sandkühler, J., and G. F. Gebhart (1984a) Characterization of inhibition of a spinal nociceptive reflex by stimulation medially and laterally in the midbrain and medulla in the pentobarbital-anesthetized rat. Brain Res. 305: 67-76.

Sandkühler, J., and G. F. Gebhart (1984b) Relative contributions of the nucleus raphe magnus and adjacent medullary reticular formation to the inhibition by stimulation in the periaqueductal gray of a spinal nociceptive reflex in the pentobarbital-anesthetized rat. Brain Res. 305: 77-87.

Saper, C. B., and A. D. Loewy (1980) Efferent connections of the parabrachial nucleus in the rat. Brain Res. 197: 291-317.

Satoh, K., M. Tohyama, K. Yamamoto, T. Sakumoto, and N. Shimizu (1977) Noradrenaline innervation of the spinal cord studied by the horseradish peroxidasc method with monoaminc oxidasc staining. Exp. Brain Res. 30: 175-186.

Sawchenko, P. E., and L. W. Swanson (1982) The organization of noradrenergic pathways from the brain stem to the paraventricular and supraoptic nuclei in the rat. Brain Res. Rev. 4: 275-322.

Schmauss, C., D. L. Hammond, J. W. Ochi, and T. L. Yaksh (1983) Pharmacological antagonism of the antinociceptive effects of serotonin in the rat spinal cord. Eur. J. Pharmacol. 90: 349-357.

Segal, M., and D. Sandberg (1977) Analgesia produced by electrical stimulation of catecholamine nuclei in the rat brain. Brain Res. 12: 369-372.
Senba, E., M. Tohyama, S. Shiosaka, H. Takagi, H. Sakanaka, T. Matsuzaki, Y. Takahashi, and N. Shimizu (1981) Experimental and morphological studies of the noradrenaline innervations of the nucleus tractus spinalis nervi trigemini of the rat with special reference to their fine structures. Brain Res. 206: 39-50.

Snyder, S. H., and S. J. Peroutka (1980) Multiple neurotransmitter receptors: Two populations of serotonin receptors with different physiological functions. In Psychopharmacology and Biochemistry of Neurotransmitter Receptors, H. I. Yamamura, R. W. Olsen, and E. Usdin, eds., pp. 313-324, Elsevier, New York.

Takano, Y., J. E. Martin, S. E. Leeman, and A. D. Loewy (1984) Substance $\mathrm{P}$ immunoreactivity released from rat spinal cord after kainic acid excitation of the ventral medulla oblongata: A correlation with increases in blood pressure. Brain Res. 291: 168-172.

Tseng, L.-F., S. S. Cheng, and J. M. Fujimoto (1983) Inhibition of tail flick and shaking responses by intrathecal and intraventricular D-Ala ${ }^{2}-$ D-Leu ${ }^{5}$-enkephalin and $\beta$-endorphin in anesthetized rats. J. Pharmacol. Exp. Ther. 224: 51-54.

Verhaart, W. J. C. (1957) The lateral reticular nucleus of medulla oblongata and the passing fiber systems of the lateral funiculus. Acta Psychiatr. Neurol. Scand. 32: 211-229.

Walberg, F. (1952) The lateral reticular nucleus of the medulla oblongata in mammals. A comparative anatomical study. J. Comp. Neurol. 96: 283-343.

Westlund, K. N., and J. D. Coulter (1980) Descending projections of the locus coeruleus and subcoeruleus/medial parabrachial nuclei in monkey: Axonal transport studies and dopamine- $\beta$-hydroxylase immunocytochemistry. Brain Res. Rev. 2: 235-264.

Westlund, K. N., R. M. Bowker, M. G. Ziegler, and J. D. Coulter (1983) Noradrenergic projections to the spinal cord of the rat. Brain Res. 263: $15-31$.

Yaksh, T. L., and T. A. Rudy (1976) Chronic catheterization of the spinal subarachnoid space. Physiol. Behav. 17: 1031-1036.

Zorman, G., G. Belcher, J. E. Adams, and H. L. Fields (1982) Lumbar intrathecal naloxone blocks analgesia produced by microstimulation of the ventromedial medulla in the rat. Brain Res. 236: 77-84.

Zorman, G., I. D. Hentall, J. E. Adams, and H. L. Fields (1981) Naloxone-reversible analgesia produced by microstimulation in the rat medulla. Brain Res. 219: 137-148. 